\title{
Perceptual Fading of a Stabilized Cortical Image: Replication in the Undergraduate Classroom
}

\author{
Nicole B. Massa, Jacob H. Deck, and Michael A. Grubb \\ https://doi.org/10.1523/ENEURO.0323-21.2021 \\ Department of Psychology and Neuroscience Program, Trinity College, Hartford, CT 06106
}

\begin{abstract}
Prolonged exposure to a stimulus causes desensitization of cortical neurons and results in perceptual changes. One example of this phenomenon is contrast adaptation, in which perceived differences between light and dark regions of a stimulus decrease. Blakemore, Muncey, and Ridley reported evidence for the "perceptual fading of a stabilized cortical image" in a 1971 Nature paper. Our goal was to replicate their second experiment, in which adaptation was measured across many contrasts, and develop an active learning exercise for undergraduate students. The experiment was coded using an open-source python package and psychophysical data were collected from two observers. On each trial, a sinusoidally modulated luminance grating appeared above fixation, and the task of the observer was to adjust the contrast of a grating below fixation until the two appeared identical. Between trials in the adaptation condition, a high contrast grating was presented in the top location; no such grating appeared between trials in the control condition. Contrast matches showed a clear reduction during the adaptation condition, thus demonstrating perceptual fading and a successful replication of Blakemore et al. (1971). We then simplified the approach and modified the code to create a single, seamless experience for use in the classroom. With instructions and theoretical background provided in a one-page handout, students can perform the experiment on themselves and view their results in an automatically generated figure. This exercise, a primary example of active learning, will help students gain a first-hand understanding of the perceptual effects of adaptation.
\end{abstract}

Key words: active learning; adaptation; contrast; undergraduate teaching

\section{Significance Statement}

Adaptation, a foundational concept in neuroscience, is a reduction in the neural response to frequent stimuli. Adaptation was reported in a 1971 Nature paper by Blakemore, Muncey, and Ridley. Here, we replicated their seminal work on adaptation using a free, open-source Python package. On each trial, observers kept their eyes on a central fixation point and adjusted the contrast of a lower grating until it looked identical to that of an upper grating. Contrast matches were made after prolonged exposure to a high-contrast grating in the upper location (adaptation condition), and when no such grating was presented (control condition). We then streamlined the experimental approach and created an active learning exercise intended for students in undergraduate neuroscience courses.

\section{Introduction}

Selective adaptation is the process by which prolonged exposure to a stimulus causes desensitization of cortical neurons, resulting in perceptual changes (Goldstein and Brockmole, 2016; Snowden et al., 2012). Adaptation is

Received July 26, 2021; accepted September 7, 2021; First published September 16, 2021.

The authors declare no competing financial interests. critical for efficient neural coding, and its effects have been well characterized at the psychological and neural levels (for review, see Clifford, 2002; Krekelberg et al., 2006; Webster, 2011). Adaptation aftereffects are ubiquitous in the sensory domain and lead to marked biases in

Author contributions: N.B.M., J.H.D., and M.A.G. designed research; N.B.M. and J.H.D. performed research; N.B.M., J.H.D., and M.A.G. analyzed data; N.B.M., J.H.D., and M.A.G. wrote the paper. 
perception. Judging the orientation of a line, for example, is systematically biased by first viewing a line of differing orientation (Gibson and Radner, 1937). Analogous results have been reported for motion direction (Levinson and Sekuler, 1976), velocity (Goldstein, 1957), and even high-level facial attributes like gender (Webster et al., 2004) and attractiveness (Rhodes et al., 2003).

Seminal work on the effects of adaptation on perceived contrast was reported in Nature by Blakemore et al. (1971). In their foundational experiments, they used two oscilloscope screens, separated by a luminous horizontal fixation bar, to display an "upper" and "lower" grating stimulus. Blakemore and Muncey both acted as observers. Their task was to adjust the lower grating's contrast to match that of the upper grating using a logarithmic potentiometer. In their experiment 1 , the upper grating was presented at two contrast levels $(0.7,0.32)$ and prolonged exposure to a high contrast grating in the upper location led to a reduction in apparent contrast for both test contrasts. This effect was observed within $\sim 30 \mathrm{~s}$ of initial exposure and reached maximal magnitude within $\sim 180 \mathrm{~s}$. In their experiment 2 , various contrast levels were used, the contrast of the upper test grating varied from trial to trial, and matches were made under two conditions: adaptation and control. The adaptation condition began with 180 $s$ of fixation during which a high contrast grating $(0.7)$ was presented at the upper location. Between adaptation trials, the high contrast upper grating was displayed for $10 \mathrm{~s}$ to maintain adaptation. During the control condition, no high contrast grating was presented at the beginning of the condition or between trials. The resulting data indicated (1) perceptual fading occurred as a result of adaptation (i.e., the lower grating needed less contrast to match the perceived contrast of the upper grating), and (2) this effect was more pronounced at lower contrasts. Here, our goal was to replicate Blakemore, Muncey, and Ridley's experiment 2 and to develop an active learning exercise for use in undergraduate psychology and neuroscience courses.

As the name implies, active learning requires that students actively participate in the process of knowledge acquisition, rather than passively receive it (Bonwell and Eison, 1991). Ample empirical evidence confirms that student engagement in the learning process results in improved recall and greater conceptual understanding (for review, see Prince, 2004). In an oft-cited example from physics education with over 6000 high-school and college students, Hake found that students in classes that promoted interactive-engagement methods, compared with students in traditional lecture-based classes, showed

This work was supported by Trinity College startup funding (M.A.G.) and Trinity College summer research grants (N.B.M. and J.H.D.).

Acknowledgements: We thank two anonymous reviewers for helpful feedback and suggestions.

Correspondence should be addressed to Michael A. Grubb at michael. grubb@trincoll.edu.

https://doi.org/10.1523/ENEURO.0323-21.2021

Copyright (C) 2021 Massa et al.

This is an open-access article distributed under the terms of the Creative Commons Attribution 4.0 International license, which permits unrestricted use, distribution and reproduction in any medium provided that the original work is properly attributed. significantly greater improvement from pre-test to posttest (Hake, 1998). Similarly, Yoder and Hochevar (2005) found that psychology students' performance on multiple-choice examination items was better when the question's material had been covered with active learning techniques compared with other formats.

With the active learning exercise provided in this article, we hope to similarly improve students' conceptual understanding of adaptation. We provide a one-page handout for use as homework assignment or (time-permitting) in-class activity, with links to the necessary open-source PsychoPy code and detailed instructions for downloading and running the experiment. During this $\sim 45$-min active learning exercise, students will be able to observe evidence of contrast adaptation within their own visual systems and deepen their understanding of this foundational concept.

\section{Materials and Methods}

\section{Replication of Blakemore et al. (1971) Observers}

Two undergraduate researchers (one woman, one man), aged 19, who are also authors of this manuscript, volunteered to participate in the study. Both were assigned the same experimental task. Informed consent was obtained from both observers and procedures were approved by the Trinity College Institutional Review Board.

\section{General procedure}

In both experimental conditions (i.e., adaptation, control), the observer maintained fixation for the duration of the experiment. Using the computer mouse to control an interactive slider, the observer attempted to match the perceived contrast of the lower grating to that of the upper grating as quickly and accurately as possible. Once a contrast match had been made, they pressed " $d$ " on the keyboard to submit the response.

\section{Stimuli}

On a full screen, mid-gray background, two vertical sinusoidally-modulated luminance gratings enveloped in a Gaussian mask [spatial frequency, three cycles per degree; size, $3 \times 3$ degrees of visual angle (DVAs)] were positioned three DVA above and below a central fixation point (white,$+ 0.5 \times 0.5 \mathrm{DVA})$. A white line representing an interactive slider was positioned below the lower grating. Use of this slider dynamically changed the contrast of the lower grating. The scale had 1000 incremental steps; each incremental step corresponded to a contrast from a contrast list. The contrast list consisted of 1000 values between 0.01 and 1.0 that were spaced evenly on a logarithmic scale. The value zero was added as the first number of the contrast list and corresponded with the first position of the interactive slider, thus allowing the lower grating to be effectively invisible. Each subsequent position of the slider was paired with the respective contrast level. Both the replication of Blakemore et al. (1971) and the active learning exercise were programmed in PsychoPy (Peirce and MacAskill, 2018). 


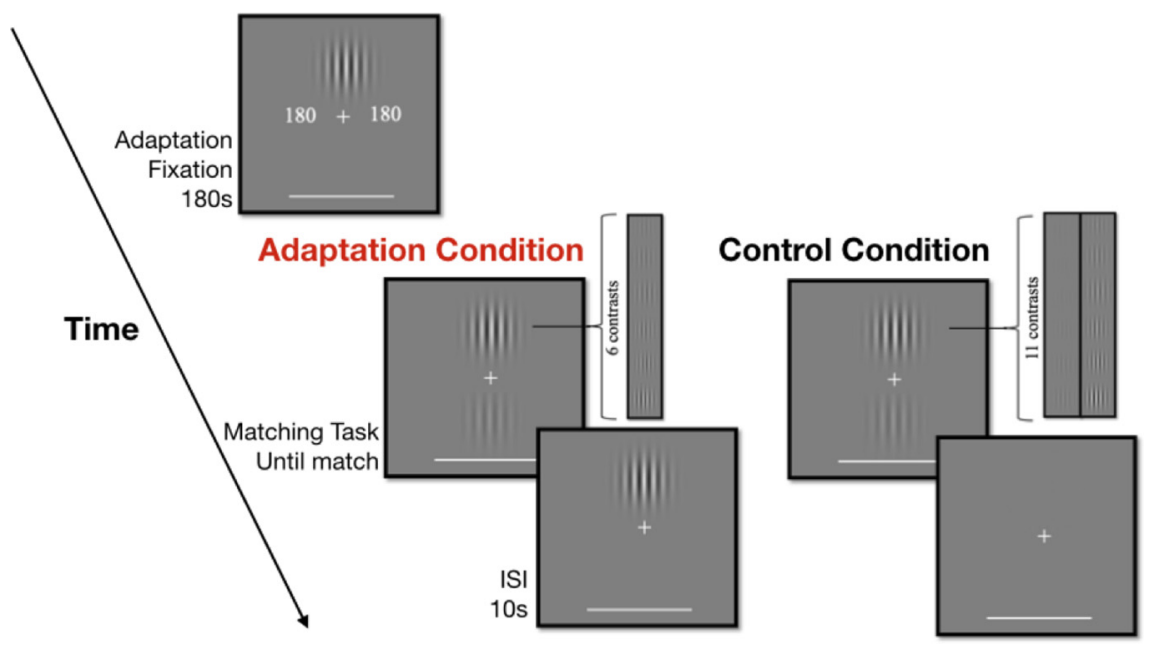

Figure 1. Blakemore et al. (1971) replication procedure. The adaptation condition began with $180 \mathrm{~s}$ of adaptation. Between each trial was a pause of $10 \mathrm{~s}$, during which a high contrast grating was presented at the upper location in the adaptation condition; no such grating was shown between trials in the control condition. The contrast of the upper grating was randomly determined on each trial; 20 contrast matches were made for each contrast level within each condition. ISI, inter-stimulus interval.
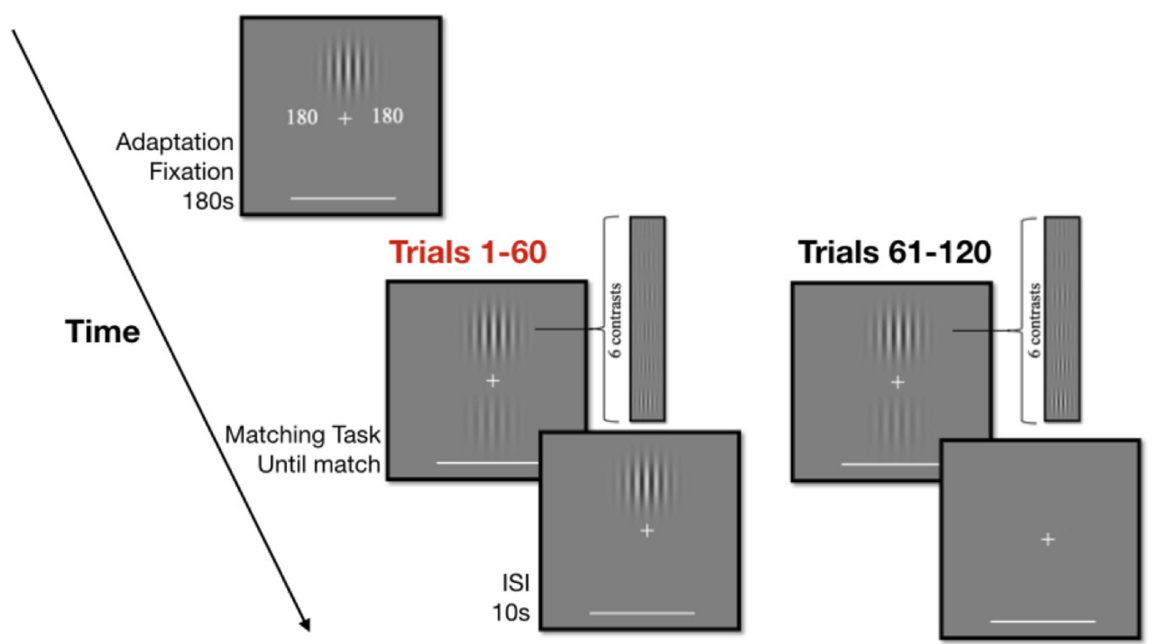

Figure 2. Active learning exercise procedure. The adaptation condition began with $180 \mathrm{~s}$ of adaptation. Between each trial was a pause of $10 \mathrm{~s}$, during which a high contrast grating was presented at the upper location in the adaptation condition; no such grating was shown between trials in the control condition. The contrast of the upper grating was randomly determined on each trial; 10 contrast matches were made for each contrast level within each condition. ISI, inter-stimulus interval.

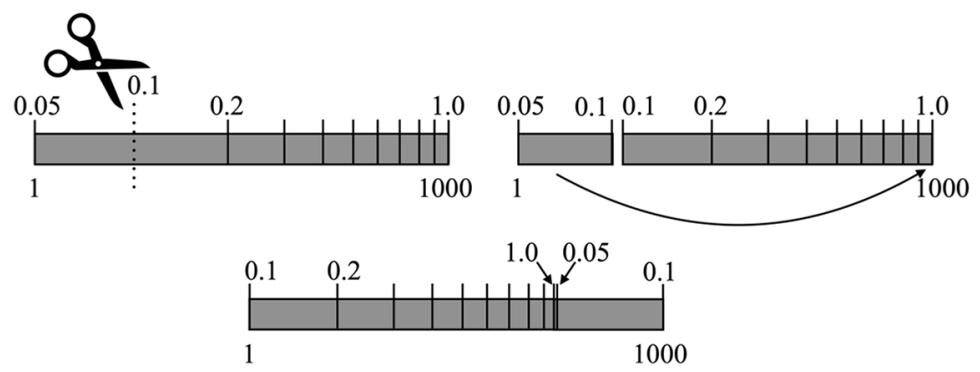

Figure 3. Sliding scale. A visual representation of the change to the sliding scale (top numbers, contrast levels; bottom numbers, position values). At a random position value, the logarithmic scale was cut. The contrast of 0.1 , which corresponded to the cut position value became the beginning of the sliding scale. All contrasts before this cut were added to the end of the scale. 


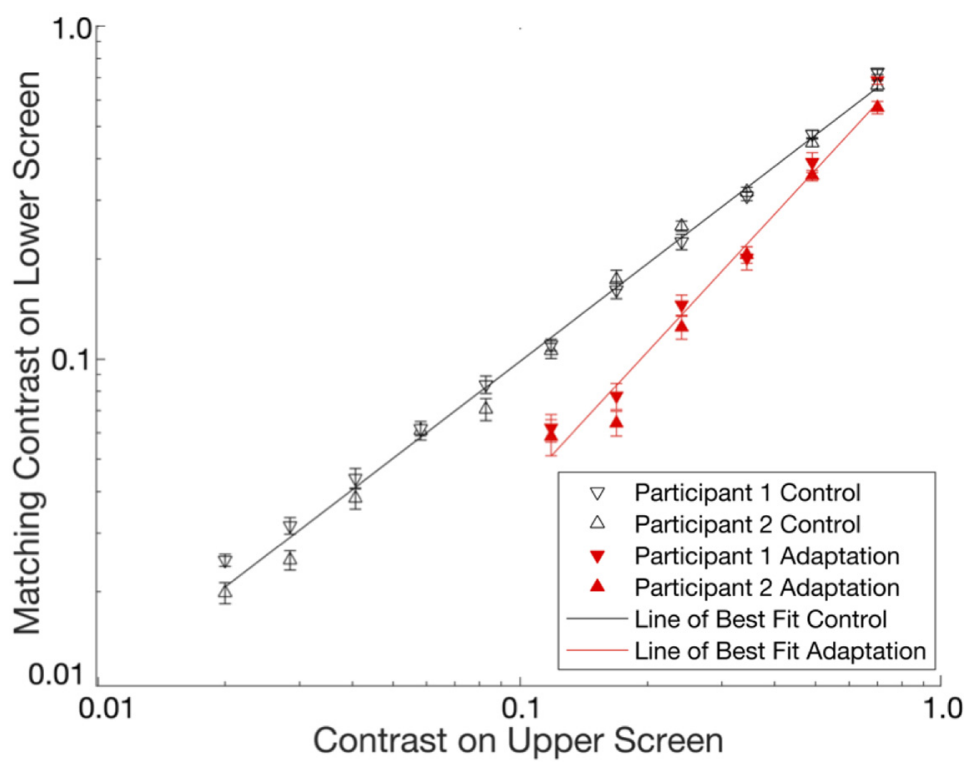

Figure 4. Blakemore et al. (1971) replication results. Perceived contrast as a function of physical contrast. Each point represents the average of 20 matches (open triangles, control condition; red triangles, adaptation condition). Error bars, standard error of the mean.

\section{Control condition}

Stimuli. The upper grating was pseudo-randomly selected to be 1 of 11 contrast values on each trial: $0.0200,0.0285$, $0.0407,0.0581,0.0829,0.1183,0.1688,0.2409,0.3438$, 0.4906 , and 0.7000 . These values were approximated from Blakemore et al. (1971; their Fig. 1).

Procedure. On each trial, the observer matched the perceived contrast of the lower grating to that of the upper grating while maintaining fixation (Fig. 1). Between each trial was a 10-s pause in which the observer was still expected to maintain fixation. There were 110 trials for each session (10 repetitions of each contrast).

\section{Adaptation condition}

Stimuli. The upper grating was pseudo-randomly selected to be 1 of 6 contrast levels for each trial: 0.1183 , $0.1688,0.2409,0.3438,0.4906$, and 0.7000 . These values were approximated from Blakemore et al. (1971; their Fig. 1).

Procedure. Before the trials began, there was a 180-s period in which the observer maintained fixation while a countdown timer (to the left and right of fixation) and an upper grating with a contrast of 0.7 were displayed (Fig. 1). Following this initial period of adaptation, the observer matched the perceived contrast of the lower grating to that of the upper grating while maintaining fixation on each trial. Between trials, this condition differed from the control condition in that a 0.7 contrast upper grating was displayed for 10 s. There were 60 trials for each session (10 repetitions of each contrast).

Table 1: Statistical summary

\begin{tabular}{lll}
\hline Data structure & Type of test & Power \\
\hline Normal distribution & Linear mixed effects model & $95 \% \mathrm{Cls}$
\end{tabular}

\section{Data analysis and statistics}

Following the analysis reported in Blakemore et al. (1971), we took the mean across contrast matches (20 repetitions) made for each contrast level, separately for each condition (control, adaptation) and separately for each observer. We then used linear regression to fit a straight line to log-transformed data (pooling across observers as in Blakemore et al., 1971), separately for each condition.

As a complement to the Blakemore et al. (1971) replication analysis, we also fit a linear mixed effects model to all of the (non-averaged) log-transformed data simultaneously (Table 1, Eq. 1). Upper grating contrast, experimental condition $(0=$ control, $1=$ adaptation $)$, and a contrast $X$ experimental condition interaction were included as fixed-effects; observer ID was included as a random effect. The two participant ID numbers (1 and 2) were included as random effects in the analysis so that the $y$-intercept of the regression line could be estimated separately for each observer, thus allowing differences in matched contrasts based on each individual's unique visual system. Analyses were completed in MATLAB (The MathWorks, 2020).

$$
\begin{gathered}
\log (\text { contrastMatch })=\beta_{0}+\beta_{1} * \log (\text { upperContrast }) \\
+\beta 2 * \text { isAdaptation }+\beta_{3} * \log (\text { upperContrast }) \\
* \text { isAdaptation }+(1 \mid \text { ID }) .
\end{gathered}
$$

(1; linear mixed effects model)

\section{Apparatus}

The experiment was conducted in the same dark, silent room with a headrest used to keep the distance and height from the screen the same for every session and observer. The same iMac (21.5-inch, 2017), 2.3 GHz Dual-Core Intel Core i5, 8 GB 2133 MHz DDR4, Intel Iris Plus Graphics 640 $1536 \mathrm{MB}$ computer was used for all sessions of the experiment, with the screen brightness set to the highest setting. 
Table 2: Simple linear models

\begin{tabular}{|c|c|c|c|c|c|c|c|}
\hline $\begin{array}{l}\text { Model } \\
\text { information }\end{array}$ & $\begin{array}{l}\text { Number of } \\
\text { observations }\end{array}$ & $\begin{array}{l}\text { Error degrees } \\
\text { of freedom }\end{array}$ & $\begin{array}{l}\text { Root mean } \\
\text { squared error }\end{array}$ & $R^{2}$ & $\begin{array}{l}\text { Adjusted } \\
\mathrm{R}^{2}\end{array}$ & $\begin{array}{l}\text { F statistic vs } \\
\text { constant model }\end{array}$ & $p$ value \\
\hline Control condition & 22 & 20 & 0.0853 & 0.994 & 0.994 & $3.61 \mathrm{E}+03$ & $4.52 \mathrm{E}-24$ \\
\hline Adaptation condition & 12 & 10 & 0.137 & 0.978 & 0.976 & 445 & $1.27 \mathrm{E}-09$ \\
\hline Estimated coefficients & Estimate & SE & $95 \% \mathrm{Cl}$ & & & t statistics & $p$ value \\
\hline \multicolumn{8}{|l|}{ Control condition } \\
\hline Intercept & -0.07842 & 0.039006 & \multirow{2}{*}{\multicolumn{2}{|c|}{$\begin{array}{l}{[-0.1598,0.0029]} \\
{[0.9380,1.0055]}\end{array}$}} & & -2.0105 & 0.05806 \\
\hline log(upperContrast) & 0.97174 & 0.016167 & & & & 60.106 & 4.5188E-24 \\
\hline \multicolumn{8}{|l|}{ Adaptation condition } \\
\hline Intercept & -0.039806 & 0.090256 & \multirow{2}{*}{\multicolumn{2}{|c|}{$\begin{array}{l}{[-0.2409,0.1613]} \\
{[1.2295,1.5197]}\end{array}$}} & & -0.44104 & 0.66857 \\
\hline log(upperContrast) & 1.3746 & 0.065132 & & & & 21.105 & 1.2679E-09 \\
\hline
\end{tabular}

Full results. Data and analysis code are available as Extended Data 1. SE, standard error; Cl, confidence interval; DF, degrees of freedom.

\section{Active learning exercise}

Observers. The same two observers from the Blakemore et al. (1971) replication experiment completed the active learning exercise.

Procedure. The observers first completed 6, non-recorded practice trials, similar in structure to the control trials of the replication experiment. Upon further instruction, they began 60 control trials (10 repetitions for each contrast). On each trial, the observer matched the perceived contrast of the lower grating to that of the upper grating while maintaining fixation (Fig. 2). Between each trial was a 10-s pause in which the participant was still expected to maintain fixation. After the control condition, the participant had the option to take a break before the $180 \mathrm{~s}$ adaptation period. During the adaptation period, the participant maintained fixation while a countdown timer (to the left and right of fixation) and an upper grating with a contrast of 0.7 were displayed (Fig. 2). Following this initial period of adaptation, the participant did the same matching task during the 60 adaptation trials (10 repetitions for each contrast). Between trials, this condition differed from the control condition in that a 0.7 contrast upper grating was displayed for $10 \mathrm{~s}$. A figure displaying the data and lines of best fit for the average matched contrasts as a function of the top contrast for each condition was automatically created and saved to the observer's computer (see Fig. 5), as was a CSV file with the raw data used to make the figure.
Stimuli. The adaptation and control conditions used the same six contrast levels from our replication experiment $(0.1183,0.1688,0.2409,0.3438,0.4906$, and 0.7000). All contrasts levels were used an equal number of times, and the level was random determined on each trial.

To prevent any potential undue influence of the interactive slider's settings on an untrained observer's judgements, we modified the slider for the active learning exercise. The scale still had 1000 incremental steps, with each incremental step corresponding to a contrast from a contrast list. The contrast list consisted of 1000 values between 0.05 and 1.0 that were spaced evenly on a logarithmic scale. Each subsequent position of the slider was paired with the respective contrast level. On each trial, the logarithmic scale was cut at a random point. The contrast level corresponding to this random point became newly paired with the smallest position value. All greater contrasts shifted down in position value; all lesser contrasts were added to the right-most end of the scale (Fig. 3). This forces the observer to actually sample the slider scale on each trial, rather than allowing them to rely on memories of settings used in former trials.

\section{Code accessibility}

The data and analysis code described in the paper are freely available online at https://attentionperceptiondecision. com/adaptation/. Both are available as Extended Data 1 and Extended Data 2.

Table 3: Contrast match data



Each observer's mean (SD in parentheses) of 20 matches for each upper contrast in the control and adaptation conditions. 
Table 4: Linear mixed effects model

\begin{tabular}{|c|c|c|c|c|c|c|}
\hline $\begin{array}{l}\text { Model } \\
\text { information }\end{array}$ & $\begin{array}{l}\text { Number of } \\
\text { observations }\end{array}$ & \multicolumn{2}{|c|}{$\begin{array}{l}\text { Fixed effects } \\
\text { coefficients }\end{array}$} & \multicolumn{2}{|c|}{$\begin{array}{l}\text { Random effects } \\
\text { coefficients }\end{array}$} & $\begin{array}{l}\text { Covariance } \\
\text { parameters } \\
\end{array}$ \\
\hline Model fit statistics & $\begin{array}{l}680 \\
\mathrm{AIC} \\
250.85\end{array}$ & $\begin{array}{l}4 \\
\mathrm{BIC} \\
277.98\end{array}$ & & $\begin{array}{l}2 \\
\text { LogLikeliho } \\
-119.42\end{array}$ & & $\begin{array}{l}2 \\
\text { Deviance } \\
238.85\end{array}$ \\
\hline Effect & Estimate & SE & $95 \% \mathrm{Cl}$ & t statistics & DF & $\mathrm{p}$ value \\
\hline Fixed effects & & & & & & \\
\hline $\begin{array}{l}\text { Intercept } \\
\text { Condition }(0=\text { control, } 1 \text { = adaptation) } \\
\text { log(upperContrast) } \\
\text { Condition:log(upperContrast) }\end{array}$ & $\begin{array}{l}-0.084 \\
0.052 \\
0.982 \\
0.443\end{array}$ & $\begin{array}{l}0.042 \\
0.052 \\
0.012 \\
0.033\end{array}$ & $\begin{array}{l}{[-0.167,-0.002]} \\
{[-0.049,0.153]} \\
{[0.958,1.006]} \\
{[0.378,0.507]}\end{array}$ & $\begin{array}{l}-2.0019 \\
1.0036 \\
80.523 \\
13.453\end{array}$ & $\begin{array}{l}676 \\
676 \\
676 \\
676\end{array}$ & $\begin{array}{l}0.045699 \\
0.31595 \\
0 \\
1.0013 E-36\end{array}$ \\
\hline $\begin{array}{l}\text { Random effects } \\
\text { ID } \\
\text { Error }\end{array}$ & $\begin{array}{l}0.0424 \\
0.2875\end{array}$ & & $\begin{array}{l}{[0.013955,0.12908]} \\
{[0.27262,0.30324]}\end{array}$ & & & \\
\hline
\end{tabular}

Full results. Data and analysis code are available as Extended Data 1.

\section{Results}

Replication of Blakemore et al. (1971)

We replicated the three critical findings reported in Blakemore and colleagues' experiment 2 (Fig. 4). First, the slope of the best-fitting line for contrast matches made during the control condition was effectively +1 [slope $=0.97174$, 95\% confidence interval $(\mathrm{Cl})=[0.9380-1.0055]$; Table 2]. Second, adaptation to a high contrast grating altered perceived contrast: relative to the control condition, average contrast matches during adaptation were reduced at all tested contrasts (Table 3). Third, this reduction in apparent contrast was more pronounced at lower contrast levels: the slope of the best-fitting line for contrast matches made during adaptation was greater than +1 (slope $=1.3746,95 \% \mathrm{Cl}=$ [1.2295-1.5197]; Table 2).

A linear mixed effects model that fit all data simultaneously and included observer as a random effects parameter provided converging results (Table 1): the upper contrast $x$ adaptation condition interaction was significantly greater than zero and its $95 \% \mathrm{Cl}$ excluded zero as a potential value (estimate $=0.44263, p=1.0013 \mathrm{e}-36,95 \% \mathrm{Cl}=[0.37803-$ 0.50724 ]; see Table 4 for full reporting).

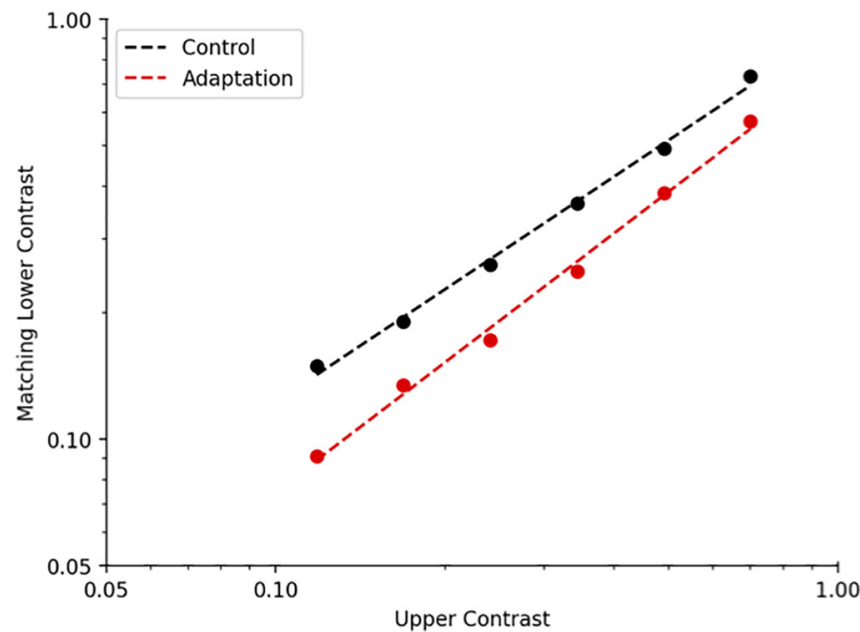

\section{Active learning exercise}

The primary result of Blakemore, Muncey, and Ridley's experiment 2 was replicated for both observers in the active learning exercise. For all contrast levels, average contrast matches during adaptation trials were reduced relative to control trials (Fig. 5).

\section{Discussion}

The purpose of this study was to replicate the second experiment of Blakemore et al. (1971), in which adaptation was measured across many contrast levels, and to develop an interactive activity on adaptation for undergraduate students. The results of the replication experiment strongly supported Blakemore, Muncey, and Ridley's findings that adaptation leads to a decrease in perceived contrast and that this decrease is more apparent at lower contrast levels. The active learning exercise produced converging results.

We envision the active learning exercise being implemented in undergraduate neuroscience and psychology classes that cover adaptation. Using our open-source experiment code, students can collect psychophysical data

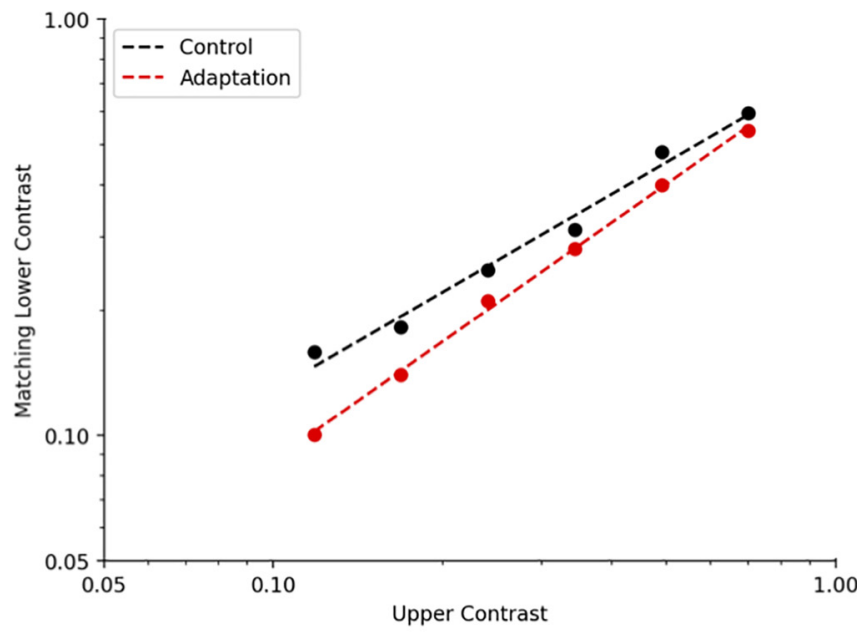

Figure 5. Active learning exercise results. Perceived contrast as a function of physical contrast for two example observers. Each point represents the average of ten matches (black dots, control condition; red dots, adaptation condition). 


\section{Selective Adaptation}

\section{Background}

In this activity, you will complete an experiment that demonstrates selective adaptation. In primary visual cortex, neurons are "tuned" to specific features of visual stimuli. For example, a vertically oriented bar of light at a particular place in the visual field will generate a large response from a subset of simple cortical cells. A different subset of neurons won't respond vigorously to the vertical stimulus but will increase their firing rates above baseline if the bar of light is rotated to a different orientation (e.g., horizontal). When exposure to a preferred stimulus persists (i.e., the visual stimulus to which a cell is tuned remains visible and in the same place), firing rates quickly decrease, and the neurons fire less when the preferred stimulus is presented again after a short break. This process is called adaptation; it is selective because only those neurons that respond to the specific stimulus adapt. Other features also impact the firing rates of visual cortical neurons. One such example is contrast. Contrast is the difference between the light and dark parts of a stimulus. The more drastic this difference, the greater the contrast and the larger the cell's response.

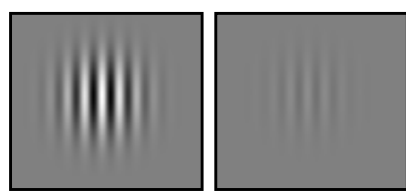

Fig 1. Gabor gratings. The left grating has more contrast than the right grating.

\section{Foundational Research}

Adaptation was explored in a seminal 1971 Nature paper by Blakemore, Muncey, and Ridley. They used vertically orientated gratings (Figure 1) and made perceptual matches. On each trial, they kept their eyes on a central fixation point and adjusted the contrast of a lower grating until it looked identical to that of an upper grating. They first showed that the effect of adaptation reaches its peak within $\sim 3$ minutes. They then assessed the magnitude of the adaptation effect across a range of different contrasts. They found that adaptation was present at all tested contrasts, but it was strongest for stimuli with low contrast. In fact, some low contrast stimuli became impossible to see during the adaptation condition, dropping below the absolute threshold for detection!

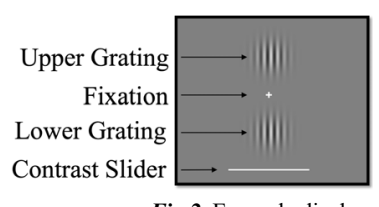

\section{Experiment Structure}

In this activity, you will use an interactive slider to match the contrast of a lower grating to an upper grating while looking at a fixation point (Figure 2). Figure 3 shows the sequence of trials for the whole experiment. In both the adaptation (Trials 1-60) and control (Trials 61-120) conditions, the upper grating can be one of six different contrasts. The adaptation condition begins with 180 seconds of viewing a high contrast upper grating. Between each trial is a pause of ten seconds, during which a high contrast upper grating will be presented in the adaptation condition; no such grating will be shown between trials or at the beginning of the control

Fig 2. Example display. condition. Figure 4 shows example results; at all contrasts, adaptation decreases the amount of contrast needed to match the bottom grating to the top. The experiment will take $\sim 45$ minutes. Your data will be automatically analyzed, and a figure will be generated for you. Click the link below to get started.

\section{AttentionPerceptionDecision.com/adaptation/}

\section{Recommended Readings}

Blakemore, C., Muncey, J. P. J., \& Ridley, R. M. (1971). Perceptual Fading of a Stabilized Cortical Image. Nature, 233(5316), 204-205.

Chapter 3 of: Goldstein, E. B., \& Brockmole, J. R. (2017). Sensation and Perception. Cengage Learning.

Krekelberg, B., Boynton, G. M., \& van Wezel, R. J. A. (2006). Adaptation: From Single Cells to BOLD Signals. Trends in Neurosciences, 29(5), 250-256.

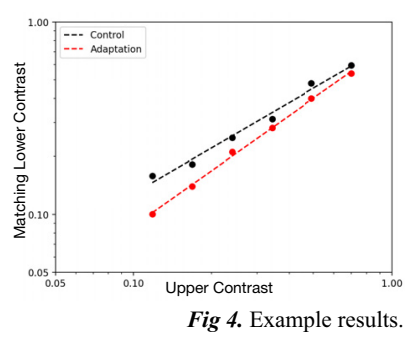

Figure 6. Active learning exercise handout. Experiment code and download instructions available as Extended Data 1. 
on themselves, have those data automatically analyzed, and review an auto-generated figure. Professional testing equipment is not required. The $\sim 45$-min activity could be assigned for homework or form part of a learning plan in a longer classroom session (e.g., a lab). Students will first read a one-page handout (Fig. 6) that provides background on perceptual adaptation, summarizes Blakemore, Muncey, and Ridley's foundational study, and introduces the structure of the active learning activity. The handout contains a URL where students can find detailed instructions on how to download PsychoPy and run the experimental code. Once finished, a CSV file containing the raw data and a figure visualizing the results (Fig. 5) will be saved to the student's computer allowing for immediate discussion of the outcome. As an advanced extension to this activity, students can use the CSV file to analyze the raw data and recreate the automatically-generated figure.

Additionally, this activity can be used to prompt a discussion on psychophysical experiment classification, specifically, Brindley's "Class A" and "Class B" distinction. Class A experiments are comprised of trials with correct and incorrect answers, resulting in quantifiable data that can be used to understand the physiological mechanisms involved in perception (Brindley, 1960; Morgan et al., 2013; Kingdom and Prins, 2016). In contrast, Class B experiments focus on the subjective qualities of the stimuli and contextual impacts on appearance. In the case of adaptation, Class B experiments can be powerful and instructive (e.g., after adapting to a green stimulus, a red afterimage will appear on a white surface), but they lack the objectivity of the contrast matching approach used in Blakemore, Muncey, and Ridley's study and replicated here. After discussing the distinction between these two classes of psychophysical experiments, the discussion can transition to linking these neuroscience methods to epistemology (i.e., how we know what we know) and philosophy of mind.

Two of the authors of this paper, who are undergraduate students themselves, are confident that these kinds of interactive activities will be more effective in deepening students' understanding of the material. This is consistent with the empirical literature on active learning (Prince, 2004), and we hope students will better retain course information that is complemented by this active learning activity. Using our successful experiences as a guide, our active learning activity caters to students who learn better through visuals and experiences. By making the active learning exercise version of our adaption experiment publicly available, we aim to deepen students' understanding of the foundational topic of adaptation.

\section{References}

Blakemore C, Muncey JP, Ridley RM (1971) Perceptual fading of a stabilized cortical image. Nature 233:204-205.

Bonwell CC, Eison JA (1991) Active Learning: Creating Excitement in the Classroom. ASHE-ERIC Higher Education Report, Washington DC: School of Education and Human Development, George Washington University.

Brindley GS (1960) Physiology of the retina and visual pathway. London: E. Arnold.

Clifford CWG (2002) Perceptual adaptation: motion parallels orientation. Trends Cogn Sci 6:136-143.

Gibson JJ, Radner M (1937) Adaptation, after-effect and contrast in the perception of tilted lines. I. Quantitative studies. J Exp Psychol 20:453-467.

Goldstein AG (1957) Judgments of visual velocity as a function of length of observation time. J Exp Psychol 54:457-461.

Goldstein EB, Brockmole JR (2016) Sensation and perception, Ed 10. Boston: Cengage.

Hake RR (1998) Interactive-engagement versus traditional methods: a six-thousand-student survey of mechanics test data for introductory physics courses. Am J Phys 66:64-74.

Kingdom FAA, Prins N (2016) Psychophysics a practical introduction, Ed 2. San Diego: Elsevier.

Krekelberg B, Boynton GM, van Wezel RJA (2006) Adaptation: from single cells to BOLD signals. Trends Neurosci 29:250-256.

Levinson E, Sekuler R (1976) Adaptation alters perceived direction of motion. Vision Res 16:779-781.

Morgan MJ, Melmoth D, Solomon JA (2013) Linking hypotheses underlying class a and class b methods. Vis Neurosci 30:197-206.

Peirce JW, MacAskill MR (2018) Building experiments in PsychoPy. London: Sage.

Prince M (2004) Does active learning work? A review of the research. J Eng Educ 93:223-231.

Rhodes G, Jeffery L, Watson TL, Clifford CWG, Nakayama K (2003) Fitting the mind to the world. Psychol Sci 14:558-566.

Snowden R, Thompson P, Troscianko T (2012) Basic vision an introduction to visual perception (revised ed.). Oxford: Oxford University Press.

Webster MA (2011) Adaptation and visual coding. J Vis 11:3.

Webster MA, Kaping D, Mizokami Y, Duhamel P (2004) Adaptation to natural facial categories. Nature 428:557-561.

Yoder JD, Hochevar CM (2005) Encouraging active learning can improve students' performance on Examinations. Teach Psychol 32:91-95. 